\title{
The effect of sperm morphology on the outcome of Assisted Reproductive Technology
}

\author{
HongQing Liao \\ The second affiliated hospital of South China university \\ Nanhua Xinghui Reproductive Health Hospital \\ Hengyang 421001, Hunan, China
}

\author{
Xinping Ouyang * \\ Department of Physiology, Medical College \\ University of South China \\ Hengyang, China \\ *Corresponding author: Xinping Ouyang, y1655@163.com
}

\begin{abstract}
The spermmorphology classification putforward by Macleod draw attention gradually onmale infertile evaluationin the past few years. This study by evaluating the effect of different morphology sperm rate on the outcomes of intracytoplasmic sperm injection assists the prediction of reproductive outcome and some reference.
\end{abstract}

Keywords- Intracytoplasmic sperm injection; Assisted reproductive technology

\section{INTRODUCTION}

Human Assisted Reproductive Technology (ART) coming outhas a great progress in the treat of infertility and the reproductive success ofpatients with abnormal sperm morphology has a substantial increase by intracytoplasmic sperm injection (ICSI). ICSI is a single sperm into the oocyte cytoplasm by using the method of microinjection, which will make thecombination of sperm and oocyte passive fertilization,to form a fertilizedzygote and transplant. Whether caused by a male factor infertility patients ornot need treatment by ICSI, which depends on the result of semen analysis.However, the analysis results of semen only show sperm morphology,density, activity and activity. These cannot reflect the fertilization ability ofsperm completely. We just suggest the basic sperm quality.

\section{METHODS}

The information of cycles were divided into three groups according to the rate of normal morphology sperm rate: group A (normal morphology sperm rate $>4 \%$ ), group $\mathrm{B}$ (normal morphology sperm rate $\leqslant 4 \%$ ), group $\mathrm{C}$ (normal morphology sperm rate $=0$ ). It was eventually a total of 815 cycles of group A,330 cycles of group B, a total of 115 cycles of group C. (1) Compare the following content among the three groups of the male age, the female age, duration of infertility; (2) Compare the following content among the three groups of fertilization, cleavage, goodquality embryos, embryo implantation, clinical pregnancy, ectopic pregnancy, miscarriage, multiple pregnancy; (3)Compare the following content of ejaculated sperm group and surgical sperm extraction group divided from group C: fertilization, cleavage, good quality embryos, embryo implantation, clinical pregnancy,ectopic pregnancy, miscarriage, multiple pregnancy.

\section{RESULTS}

Normal sperm morphology group (A), not severely deformed spermgroup (B) and severely deformed sperm group (C).

1.The results of the comparison are as follows:

(1) The male age in the three groups were $29.73 \pm 3.13$ years, $30.19 \pm 3.85$ years, $31.66 \pm 3.10$ years respectively. There was no significant difference among the three groups $(\mathrm{F}=0.260, \mathrm{P}>0.05)$; (2) The female age in the three groups were $29.40 \pm 3.37$ years, $30.48 \pm 3.30$ years, $31.15 \pm 2.56$ yearsrespectively. There was no significant difference among the three groups $(\mathrm{F}=0.242, \quad \mathrm{P}>0.05)$; (3) The duration of infertility in the three groups were $5.33 \pm 3.51$ years, $4.85 \pm 3.07$ years, $5.17 \pm 3.25$ years respectively. There was no significant difference among the three groups $(\mathrm{F}=0.016, \mathrm{P}>0.05)$.

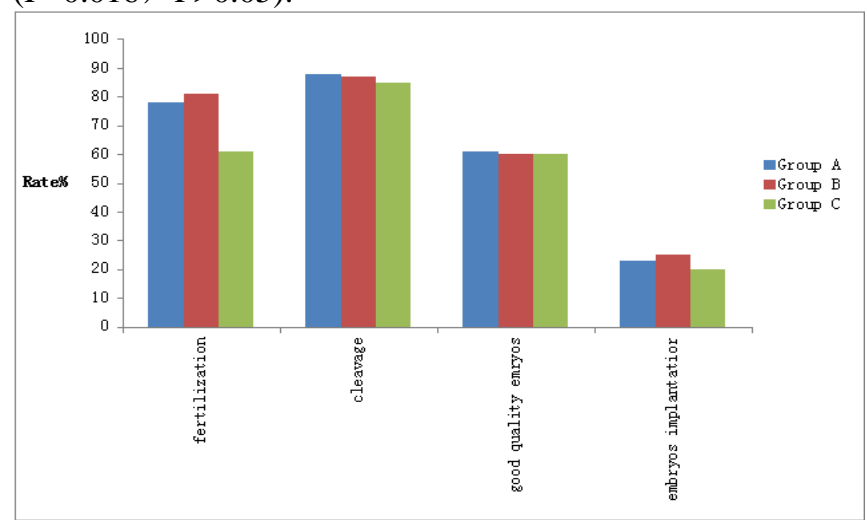

Figure 1 comparison of fertilization, cleavage, good quality embryos and embryo implantation among the three groups.

2. Compare the content among the three groups of fertilization(\%),cleavage(\%), good quality embryos(\%), embryo implantation(\%), clinical pregnancy(\%), ectopic pregnancy(\%), miscarriage(\%), multiple pregnancy(\%). 
(1) The fertilization rate in group $\mathrm{A}, \mathrm{B}$ and $\mathrm{C}$ were $78.3 \%(6906 / 8820), \quad 80.1 \%(2762 / 3450)$ and $64.5 \%$ (840/1302) respectively. There was significant difference among the three groups $(\mathrm{P}<0.05)$.Compared group $\mathrm{A}$ and group B, there was no significant difference among the two groups $(\mathrm{P}>0.01)$. Compared group $\mathrm{A}$ and group $\mathrm{C}$, there was significant difference among the two groups $\left(x^{2}\right.$ $=119.983, \mathrm{P}<0.001)$. Compared group $\mathrm{B}$ and group $\mathrm{C}$, there was significant difference among the two groups ( $x^{2}$ $=124.472, \mathrm{P}<0.001$ ); (2) The cleavage rate in group A, B and $\mathrm{C}$ were $89.3 \%(6167 / 6906), 87.8 \%(2425 / 2762)$ and $85.5 \%$ (718/840) respectively. There was no significant difference among the three groups $(\mathrm{P}>0.05)$; (3)The good quality embryos rate in group $\mathrm{A}, \mathrm{B}$ and $\mathrm{C}$ were $60.9 \%$ (3756/6167), 58.8\% (1426/2425) and 58.6\% (418/714) respectively. There was no significant difference among the three groups $(\mathrm{P}>0.05)$; (4)The embryo implantation rate in group A, B and C were $25.2 \%$ (386/1532), 27.6\% (213/771) and $23.3 \%(56 / 241)$ respectively. There was no significant difference among the three groups $(\mathrm{P}>0.05)$; (5) The clinical pregnancy rate in group A, B and C were $48.5 \%$ $(395 / 815), \quad 47.0 \%(155 / 330)$ and $33.0 \%$ (38/115) respectively. There was significant difference among the three groups $(\mathrm{P}<0.05)$. Compared group $\mathrm{A}$ and group $\mathrm{B}$, there was no significant difference among the two groups $(\mathrm{P}>0.01)$. Compared group $\mathrm{A}$ and group $\mathrm{C}$, there was significant difference among the two groups ( $x^{2}$ =9.634, $\mathrm{P}=0.002$ ). Compared group $\mathrm{B}$ and group $\mathrm{C}$, there was significant difference among the two groups ( $x^{2}$ $=6.734, \mathrm{P}=0.009$ ); (6) The ectopic pregnancy rate in group $\mathrm{A}, \mathrm{B}$ and $\mathrm{C}$ were $3.5 \%$ (14/395), $5.2 \%$ (8/155) and $7.9 \%(3 / 38)$ respectively. There was no significant difference among the three groups $(\mathrm{P}>0.05) ;(7)$ The miscarriage rate in group A, B and C were $3.8 \%$ (15/395), $5.2 \%(8 / 155)$ and $10.5 \%(4 / 38)$ respectively. There was no significant difference among the three groups $(\mathrm{P}>0.05)$; (8) The multiple pregnancy rate in group $\mathrm{A}, \mathrm{B}$ and $\mathrm{C}$ were $20.8 \%(82 / 395), \quad 18.1 \% \quad(28 / 155)$ and $23.7 \% \quad(9 / 38)$ respectively. There was no significant difference among the three groups $(\mathrm{P}>0.05)$.

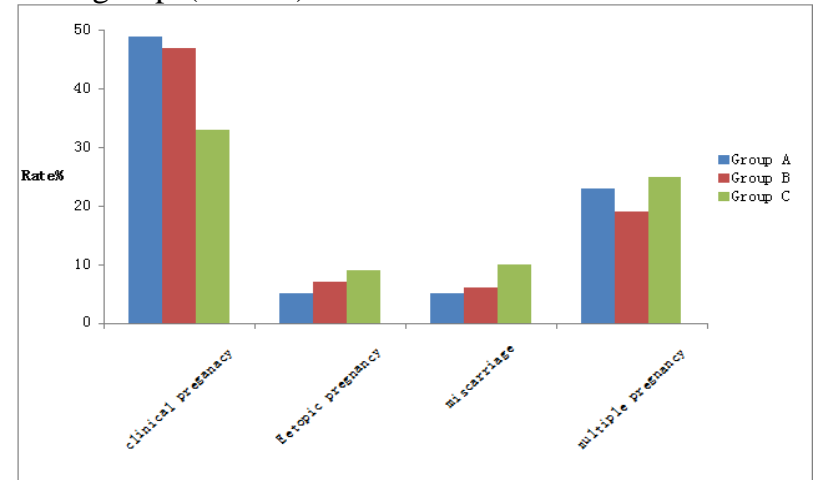

Figure 2 comparison of the outcomes among the three groups

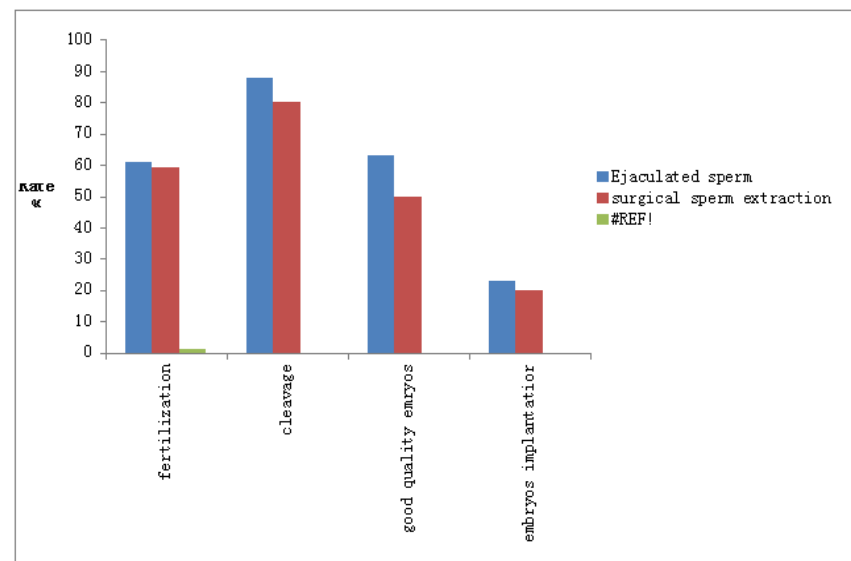

Figure 3 Comparison of fertilization, cleavage, good quality embryos and embryo implantation of ICSI by teratospermia from ejaculated sperm and surgical sperm extraction sperm.

3. In severely deformed sperm group, the comparison between ejaculated sperm group ( 1 1) and surgical sperm extraction group ( C2 ) in fertilization(\%),cleavage(\%), good quality embryos(\%), embryo implantation(\%), clinicalpregnancy $(\%), \quad$ ectopic pregnancy $(\%)$, miscarriage $(\%)$, multiplepregnancy $(\%)$.

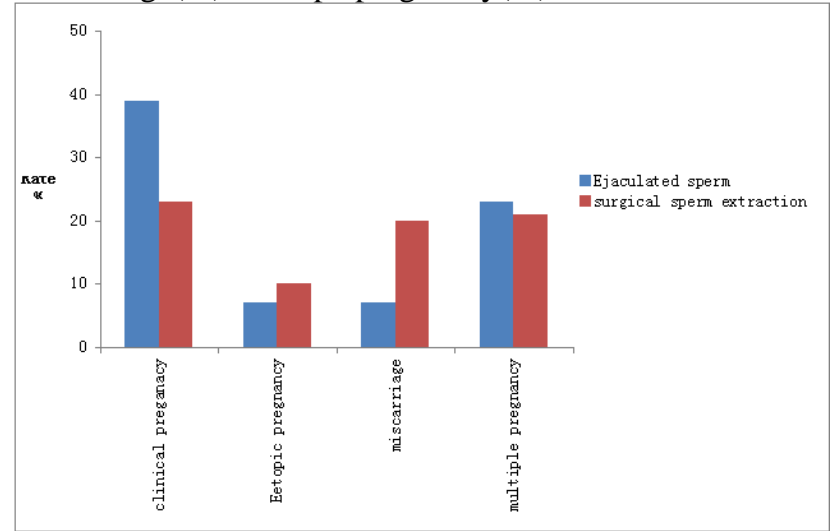

Figure 4 Comparison of the outcomes of ICSI by teratospermia from ejaculated sperm and surgical sperm extraction sperm

(1) The fertility rate in groupC1and group $\mathrm{C} 2$ is $65.7 \%$ (531/808) and62.6\% (309/494) respectively. The comparison between the two groups, there is no statistically significant difference ( $\mathrm{P}>0.05)$; (2) The cleavage rate in groupC1and group C2is 88.2\% (468/531) and $80.9 \%$ (250/309). The comparisonbetween the two groups, there is statistically significant difference $\left(\chi^{2}=8.224, \quad \mathrm{P}=0.004\right)$; (3) The good quality embryos rate in groupC1and group C2is $62.6 \%(293 / 468)$ and $50.0 \%(125 / 250)$. The comparison between the two groups, there is statistically significant difference $\left(\chi^{2}=10.647, \quad \mathrm{P}=0.001\right)$; (4) The embryo implantation rate in group C1and group C2is $25.5 \%$ (38/149) and19.6\% (18/92). The comparison between the two groups, there is no statistically significant difference ( $\mathrm{P}>0.05)$; (5)The clinical pregnancy rate in group $\mathrm{C} 1$ and group C2is $37.8 \%(28 / 74)$ and $24.4 \%$ (10/41). The 
comparisonbetween the two groups, there is no statistically significant difference $(\mathrm{P}>0.05)$; (6) The ectopic pregnancy rate in group $\mathrm{C}$ 1and group $\mathrm{C} 2$ is $7.1 \%(2 / 28)$ and $10.0 \%$ (1/10). The comparison between the two groups, there is no statistically significant difference $(\mathrm{P}>0.05)$; (7) The miscarriage rate in groupC1and group $\mathrm{C} 2$ is $7.1 \%(2 / 28)$ and $20.0 \%(2 / 10)$. The comparison between the two groups, there is no statistically significant difference $(\mathrm{P}>0.05)$; 8) The multiple pregnancy rate in group $\mathrm{C}$ land group $\mathrm{C} 2$ is $25.0 \%(7 / 28)$ and $20.0 \%(2 / 10)$. The comparison between the two groups, there is no statisticallysignificant difference $(\mathrm{P}>0.05)$.

\section{CONCLUSIONS}

Sperm-oocyte binding and the growth of fertilized zygote and embryosare same with normal sperm morphology rate, only if the sperm is normalsperm morphology, when the ICSI technology assists pregnancy. Patients whouse abnormal sperm morphology in ICSI to assists pregnancy, the fertilizationrate and clinical pregnancy rates are lower than who use normal spermmorphology. In very severely deformed sperm group, the cleavage rate andgood quality embryos rate of surgical sperm extraction group are lower thanejaculated sperm $g$ roup.

\section{REFERENCE}

[1] Collodel G, Capitani S, Iacoponi F, et al. Retrospective assessment ofpotential negative synergistic effects of varicocele and tobacco use on ultrastructural sperm morphology[J].Urology, 2009, 74(4):794-799 3

[2] Niu ZH, Liu JB, Shi TY, et al. Impact of cigarette smoking on human sperm DNA integrity[J].Zhonghua Nan Ke Xue, 2010, 16(4):300-304

[3] Taha EA, Ez-Aldin AM, Sayed SK, et al. Effect of smoking on sperm vitality, DNA integrity, seminal oxidative stress, zinc in fertile men [J].Urology, 2012, 80(4):822-825

[4] Jana K, Samanta PK, De DK. Nicotine diminishes testicular gametogenesis, steroidogenesis, and steroidogenic acute regulatory protein expression in adult albino rats: possible influence on pituitary gonadotropins and alteration of testicular antioxidant status [J].Toxicol Sci, 2010, 116(2):647-659 